\title{
Effects of Processing Factors on Mechanical Properties of "Pancake" Prepared by Hot Isostatic Pressing and Superplastic Forging from Nickel-base Alloy Powder*
}

\author{
By Shizuo NAKAZAWA, ,* Isao TOMIZUKA, ${ }^{* *}$ Yutaka KOIZUMI ${ }^{* *}$ \\ and Michio YAMAZAKI**
}

\begin{abstract}
Synopsis
Effects of processing factors on the tensile properties and creep properties at $1033 K$ were investigated for "pancakes" (thick circular disks) of a nickel-base superalloy. The pancakes were prepared by procedures comprising a rotating-disc process employing liquid-helium, hot isostatic pressing (HIP) consolidation preceded or not preceded by Attritor treatment and a superplastic forging with an apparatus specifically developed for this research. Major points of the obtained results were as follows:

(1) The HIP-consolidated material from under-60-Tyler-mesh powder could be forged in a superplastic way only at a deformation rate of 0.2 through $0.5 \times 10^{-4} / \mathrm{s}$, while that from under-150-Tyler-mesh could be at a rate of $1 \times 10^{-4} / \mathrm{s}$. The product from the coarse powder had a tensile performance a little superior to that from the fine powder.

(2) The product obtained by a superplastic forging in an economical condition (at a lower temperature and a higher forging rate) showed a larger tensile elongation and a larger creep rate than that in a prudent condition (a higher temperature and a lower forging rate).

(3) An Attritor pretreatment preceding HIP made superplastic forging easier but caused deterioration of the creep and the tensile performance.
\end{abstract}

Keywords: nickel-base superalloy; powder metallurgy; superplastic forging.

\section{Introduction}

Discs are the most expensive components in gas turbines. This is because they are fabricated by machining of a forged block of an expensive alloy. Owing to their unique shapes they require a large amount of experienced machining. In the course of the machining, moreover, more than half of the original block is wasted. Aimed at fabricating the same component at a lower cost preferably with a better performance, powder metallurgy processes, mainly on basis of consolidations by hot isostatic pressing (HIP), were introduced fairly long ago. Unfortunately, however, the performance of thus obtained products were not satisfactory. Simple HIP could not make the products tough enough.

In order to improve the situation, various types of combination of HIP and superplastic forging were attempted. Gatorizing process is their representative example. In this process, superplasticity is materialized by high-temperature extrusion of alloy powder. This extrusion, however, is the main bottleneck of the process. Since the pressure required for extrusion is enormous, a prohibitively powerful extruder is required when a gas-turbine disc is to be fabricated by this process.
Against this background, the Government of Japan is promoting a research project to fabricate this component without employing an extruder. The intended process comprises HIP-consolidation of fine alloy powder, followed by superplastic forging of the consolidated alloy block. This paper deals with a part of the results of the research work, which has been carrying out jointly with Daido Steel Co., Ltd., Kobe Steel, Ltd. and Sumitomo Electric Industries, Ltd. Main topics to be discussed here are concerned with the following three points observed when pancakes (superplastically forged thick discs) are prepared from powder of a fixed composition.

1) Effects of particle size of powder on behaviour of superplastic deformation and on performance of the pancakes.

2) Effects of the conditions of superplastic forging on behaviour of superplastic deformation and on performance of the pancakes.

3) Effect of Attritor treatment which is performed on powder before HIP-consolidation.

\section{Experimental}

\section{Alloy}

The alloy used in this experiment was a gammaprime-phase strengthened nickel-base alloy with a composition shown in Table 1. This alloy, codenamed as TMP-3, was designed and prepared specifically for this research. It was a modification of René 95 designed by a procedure developed by Harada and others. $^{2)}$ It was to contain gamma-prime-phase by $70 \%$ at temperatures around $1023 \mathrm{~K}$.

\section{Preparation of Specimens}

Five pancakes were prepared in different ways from the powder considered to be from an identical batch. Major features of each condition are shown in Table 2. Supplemental details of each procedure are as follows:

Powder making: A liquid helium cooling (LHG) process, which applies the centrifugal force of a rotating disc cooled by liquid helium, on which molten alloy is poured. Further details of the procedure and the apparatus is available from the literature. ${ }^{3)}$ An example of grain size distribution of the prepared pow-

\footnotetext{
* Originally published in Tetsu-to-Hagané, 72 (1986), 1701, in Japanese; formerly presented to the 110th ISIJ Meeting, October 1985, S1602, at Niigata University in Niigata. English version received on May 15, 1987; accepted in the final form on July 3, 1987. (C) 1987 ISIJ
}

** National Research Institute for Metals, Nakameguro, Meguro-ku, Tokyo 153. 
Table 1. Nominal composition of the alloy, TMP-3 (wt \%, Ni: bal)

\begin{tabular}{cccccccccc}
\hline Co & $\mathrm{Cr}$ & $\mathrm{Mo}$ & $\mathrm{W}$ & $\mathrm{Al}$ & $\mathrm{Ti}$ & $\mathrm{Nb}$ & $\mathrm{C}$ & $\mathrm{B}$ & $\mathrm{Zr}$ \\
\hline 6.9 & 10.8 & 3.1 & 3.4 & 3.9 & 2.8 & 3.9 & 0.07 & 0.01 & 0.05 \\
\hline
\end{tabular}

Table 3. An example of particle size distribution of powder.

\begin{tabular}{cccccccc}
\hline Mesh & +80 & +100 & +150 & +200 & +250 & +350 & -350 \\
\hline$\%$ & 3.4 & 25.6 & 42.4 & 20.5 & 3.9 & 2.8 & 1.4 \\
\hline
\end{tabular}

Table 2. Applied processes and conditions thereof.

\begin{tabular}{|c|c|c|c|c|c|c|c|c|}
\hline \multicolumn{4}{|c|}{ Conditions } & \multicolumn{5}{|c|}{ Specimens } \\
\hline Process & \multicolumn{2}{|c|}{ Factor } & Unit & $\mathrm{A}$ & $\mathrm{B}$ & $\mathrm{C}$ & $\mathrm{D}$ & $\mathrm{E}$ \\
\hline Powder making & \multicolumn{2}{|l|}{ Procedure } & & LHC & $\leftarrow$ & $\leftarrow$ & $\leftarrow$ & $\leftarrow$ \\
\hline Glassification & & & Tyler mesh & $\sim 60$ & $\sim 150$ & $\sim 150$ & $60 \sim 150$ & $60 \sim 150$ \\
\hline \multirow[t]{5}{*}{ Attritor } & \multicolumn{2}{|c|}{ Weight of balls } & $(\mathrm{kg})$ & - & - & - & 85 & $\leftarrow$ \\
\hline & \multicolumn{2}{|c|}{ Weight of powder } & $(\mathrm{kg})$ & - & - & - & 5 & $\leftarrow$ \\
\hline & \multicolumn{2}{|c|}{ Rotation } & $(\mathrm{rpm})$ & - & - & - & $195 \sim 200$ & $\leftarrow$ \\
\hline & \multicolumn{2}{|l|}{ Atmosphere } & $(-)$ & - & - & - & Ar & $\leftarrow$ \\
\hline & \multicolumn{2}{|l|}{ Time } & $(\mathrm{h})$ & - & - & - & 1 & 7 \\
\hline \multirow[t]{5}{*}{ HIP } & \multirow{2}{*}{ Initial size: } & Diameter & $(\mathrm{mm})$ & 130 & 102 & $\leftarrow$ & 72 & $\leftarrow$ \\
\hline & & Height & $(\mathrm{mm})$ & 130 & 240 & $\leftarrow$ & 70 & $\leftarrow$ \\
\hline & \multicolumn{2}{|c|}{ Temperature } & $(\mathrm{K})$ & 1373 & $\leftarrow$ & 1273 & 1453 & $\leftarrow$ \\
\hline & \multicolumn{2}{|l|}{ Pressure } & $(\mathrm{MPa})$ & 166.7 & $\leftarrow$ & 166.7 & 176.5 & $\leftarrow$ \\
\hline & \multicolumn{2}{|l|}{ Time } & (h) & 3 & $\leftarrow$ & $\leftarrow$ & 1 & $\leftarrow$ \\
\hline \multirow{6}{*}{$\begin{array}{l}\text { Superplastic } \\
\text { forging }\end{array}$} & \multicolumn{2}{|c|}{ Temperature } & $(\mathrm{K})$ & 1373 & $\leftarrow$ & 1323 & $\leftarrow$ & $\leftarrow$ \\
\hline & \multicolumn{2}{|c|}{ Rate of stressing } & $\left(\times 10^{-4} / \mathrm{s}\right)$ & $0.2 \sim 0.5$ & 1 & 2 & $\leftarrow$ & $\leftarrow$ \\
\hline & \multirow[t]{2}{*}{ Initial size: } & Diameter & $(\mathrm{mm})$ & 110 & 75 & $\leftarrow$ & 70 & 67 \\
\hline & & Height & $(\mathrm{mm})$ & 30 & 56 & $\leftarrow$ & 64 & 60 \\
\hline & \multirow[t]{2}{*}{ Final size: } & Diameter & $(\mathrm{mm})$ & 142 & 125 & 128 & $\leftarrow$ & 116 \\
\hline & & Height & $(\mathrm{mm})$ & 18 & 20 & 19 & $\leftarrow$ & 20 \\
\hline \multirow[t]{12}{*}{ Heat treatment } & \multirow{3}{*}{$\begin{array}{ll}\text { Step 1: } & \mathrm{T} \\
& \mathrm{T} \\
& \mathrm{A}\end{array}$} & nperature & $(\mathrm{K})$ & 1493 & $\leftarrow$ & $\leftarrow$ & $\leftarrow$ & $\leftarrow$ \\
\hline & & & $(\mathrm{h})$ & 2 & $\leftarrow$ & $\leftarrow$ & $\leftarrow$ & $\leftarrow$ \\
\hline & & nosphere & $(-)$ & $\mathrm{Ar}$ & $\leftarrow$ & $\leftarrow$ & $\leftarrow$ & $\leftarrow$ \\
\hline & \multirow{3}{*}{$\begin{array}{ll}\text { Step 2: } & \mathrm{T} \\
& \mathrm{T} \\
& \mathrm{A}\end{array}$} & nperature & $(\mathrm{K})$ & 1353 & $\leftarrow$ & $\leftarrow$ & $\leftarrow$ & $\leftarrow$ \\
\hline & & & $(\mathrm{h})$ & 4 & $\leftarrow$ & $\leftarrow$ & $\leftarrow$ & $\leftarrow$ \\
\hline & & nosphere & $(-)$ & $\mathrm{Ar}$ & $\leftarrow$ & $\leftarrow$ & $\leftarrow$ & $\leftarrow$ \\
\hline & \multirow{3}{*}{$\begin{array}{ll}\text { Step } 3: & \mathrm{T} \\
& \mathrm{T} \\
& \mathrm{A}\end{array}$} & nperature & $(\mathrm{K})$ & 1116 & $\leftarrow$ & $\leftarrow$ & $\leftarrow$ & $\leftarrow$ \\
\hline & & & (h) & 16 & $\leftarrow$ & $\leftarrow$ & $\leftarrow$ & $\leftarrow$ \\
\hline & & nosphere & $(-)$ & $\mathrm{Ar}$ & $\leftarrow$ & $\leftarrow$ & $\leftarrow$ & $\leftarrow$ \\
\hline & \multirow{3}{*}{$\begin{array}{ll}\text { Step 4: } & \mathrm{T} \\
& \mathrm{T} \\
& \mathrm{A}\end{array}$} & nperature & $(\mathrm{K})$ & 1033 & $\leftarrow$ & $\leftarrow$ & $\leftarrow$ & $\leftarrow$ \\
\hline & & & (h) & 24 & $\leftarrow$ & $\leftarrow$ & $\leftarrow$ & $\leftarrow$ \\
\hline & & nosphere & $(-)$ & air & $\leftarrow$ & $\leftarrow$ & $\leftarrow$ & $\leftarrow$ \\
\hline
\end{tabular}

LHG : Liquid helium cooling

der is shown in Table 3.

Classification: By screen sieving.

HIP: Performed in a steel can.

Superplastic forging: Performed with a facility specially built for this research project. A cylindrical block of HIP-consolidated powder was forged along its axis in an open mould of titanium-zirconiummolybdenum alloy (TZM). ${ }^{4}$ Although the sizes of the starting blocks were not identical as is shown in Table 4, the ratio of forging at the final stage was manipulated to be as equivalent as possible. Maximum values of the forging pressure are shown in Table 4.

Sampling of specimens: Cylindrical rods with a diameter of $7 \mathrm{~mm}$ were machined from square rods sampled from the pancakes in their radial directions. $\leftarrow:$ Same to the left

- : Attritor processing missing for these specimens

They were subjected to the four-step heat treatment shown in Table 2. The rods were left in air to cool after each step of the heat treatment.

\section{Tensile and Creep Rupture Testings}

Test pieces in the shape of Fig. 1 were machined from the cylindrical rods mentioned above and were subjected to tensile testing and creep rupture testing at $1033 \mathrm{~K}$. Rate of stretching for the tensile testing was $0.05 \mathrm{~mm} / \mathrm{min}$ until the $0.2 \%$-yield-stress and 1 $\mathrm{mm} / \mathrm{min}$ thereafter. Stress for the creep rupture testing was $593.3 \mathrm{MPa}$.

\section{Results and Discussion}

Results of tensile testing and the creep rupture testing are shown in Table 4 . 


\section{Effects of Particle Size}

Materials after HIP were more difficult to forge when the powder was coarser. In the case of the forging at $1373 \mathrm{~K} \mathrm{HIP-consolidated} \mathrm{block} \mathrm{from} \mathrm{un-}$ der-150-mesh powder could be successfully forged at a rate of $1 \times 10^{-4} / \mathrm{s}$ (Specimen $\mathrm{B}$ ), while that from under-60-mesh powder required less than half of that rate for a successful forging (Specimen A). Specimen A was better in other things. It required a lesser pressure for forging and materialized a larger ultimate strength with a smaller elongation so long as the asforged pancake was concerned.

These differences of the forging pressure and of the tensile properties well matched the structural features of both specimens. The pancake from coarse powder contained angular structure with grains fragmented to a lesser extent ( $X$ in Fig. 2(a)), while that from fine powder contained fine structure with fine and spherical grains ( $Y$ in Fig. 3(a)). The large and angular grains are liable to start to slide from each other. Once they start to do so, they will tend to form voids and cracks among them.

As is seen from a comparison of the structures after the heat treatment of Specimen A in Fig. 2(b) with the equivalent in Fig. 3(b), this structural difference almost disappeared after the heat treatment. In accordance with it, the difference of the tensile properties almost disappeared as well. The structural similarity, however, seemed to have disappeared not thoroughly. Creep rupture life was still fairly longer

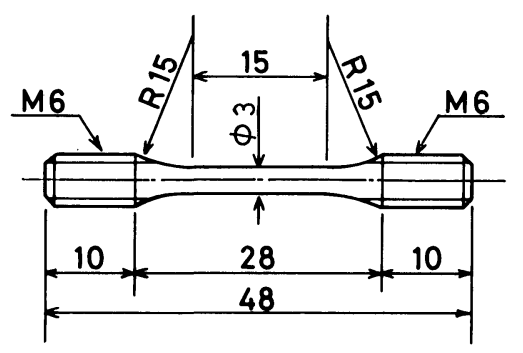

Fig. 1. Test piece for tensile and creep rupture test. for the pancake from the coarse powder.

It is not clear for the time being why our results do not agree with what is reported elsewhere. ${ }^{5)}$ Although it is a matter to be investigated, some of the members of the research project are paying attention to the difference of the oxygen contents seen in the pancakes. It is believed that the pancakes from finer powder contained a larger amount of oxygen.

\section{Effect of the Conditions of the Superplastic Forging Pro- cedure}

Since the superplastic forging of superalloys is a metallurgical process to be carried out at a high temperature in vacuum or in a controlled atmosphere by employing an expensive apparatus and taking a long operation time, forging at a low temperature and a high rate as possible has so much economical sense. Specimen $\mathrm{G}$ in Table 2 was prepared to cheek the performance of the products produced in an economi-

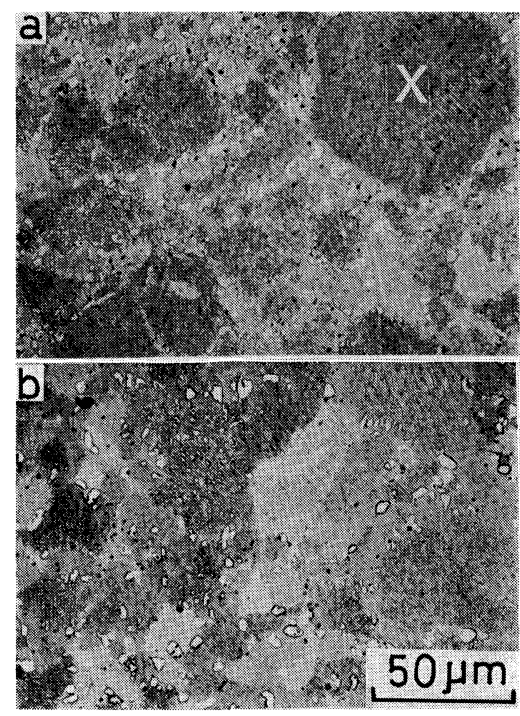

(a) Before heat treatment

(b) After heat treatment

Fig. 2. Microstructures for Specimen A.

Table 4. Numerical data for Specimens A through E.

\begin{tabular}{|c|c|c|c|c|c|c|c|}
\hline Testing & Factor & Unit & $\mathrm{A}$ & $\mathrm{B}$ & $\mathrm{C}$ & $\mathrm{D}$ & $\mathrm{E}$ \\
\hline $\begin{array}{l}\text { Maximum superplastic } \\
\text { deformation resistance }\end{array}$ & & (MPa) & 8 & 52 & 133 & 15 & 5 \\
\hline \multirow{4}{*}{$\begin{array}{l}\text { Tensile property } \\
\text { (before heat treatment) }\end{array}$} & Yield stress* & $(\mathrm{MPa})$ & 854 & 808 & 805 & 746 & 655 \\
\hline & Strength** & $(\mathrm{MPa})$ & 1166 & 1011 & 1037 & 992 & 941 \\
\hline & Elongation & $(\%)$ & 3.3 & 5.7 & 6.3 & 5.3 & 3.3 \\
\hline & Reduction in area & $(\%)$ & 10.2 & 13.7 & 13.2 & 9.5 & 7.4 \\
\hline \multirow{4}{*}{$\begin{array}{l}\text { Tensile property } \\
\text { (after heat treatment) }\end{array}$} & Yield stress* & $(\mathrm{MPa})$ & 858 & 846 & 818 & 766 & - \\
\hline & Strength** & $(\mathrm{MPa})$ & 1186 & 1174 & 1163 & 1051 & 685 \\
\hline & Elongation & $(\%)$ & 4.6 & 3.9 & 7.9 & 2.0 & 0.9 \\
\hline & Reduction in area & $(\%)$ & 8.2 & 7.6 & 4.2 & 5.0 & 4.2 \\
\hline \multirow{2}{*}{$\begin{array}{l}\text { Creep property } \\
\text { (after heat treatment) }\end{array}$} & Life & $(\mathrm{h})$ & 148.0 & 108.4 & 72.9 & 13.7 & 1.4 \\
\hline & Elongation & $(\%)$ & 4.7 & 3.4 & 3.5 & 1.9 & 1.0 \\
\hline
\end{tabular}

* $0.2 \%$ yield stress

** Ultimate tensile strength 


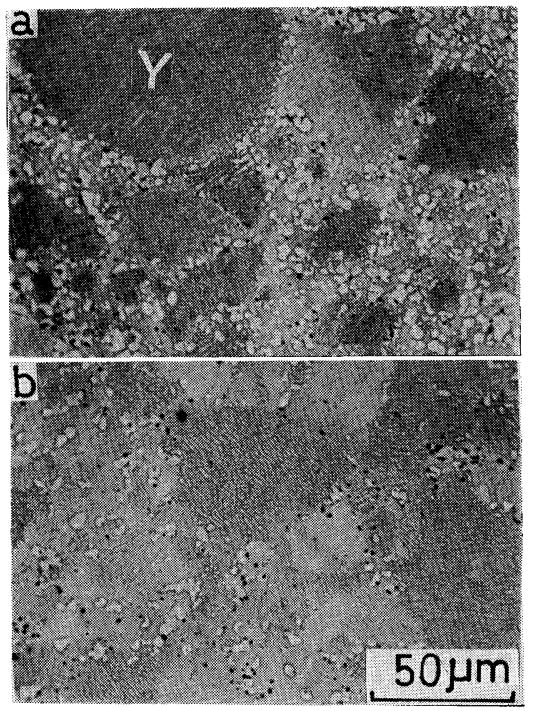

(a) Before heat treatment

(b) After heat treatment

Fig. 3. Microstructures for Specimen B.

cal condition, i.e., at a lower temperature and a higher strain rate. In addition to a foregone result that the forging pressure changed, the data in Table 4 revealed that the change of the operational condition caused a considerable difference of the mechanical properties of the products. While the mechanical properties were almost the same in the as-forged condition, Specimen $\mathrm{C}$ after the heat treatment showed as twice as large elongation and a considerably larger creep life (this means a larger creep rate, since their creep elongations were almost identical) as compared with Specimen B after the same heat treatment. Economical forging condition caused a softening of the products after heat treatment. The larger softening is well understandable by observation of the obvious change of the structure from Figs. 4(b) and 3(b). While the grain boundaries in Specimen B are decorated with a wide, dispersion of coarse precipitates, those in Specimen C appear a thin layer of precipitates. It is well established that an alloy with straight grain boundaries with filmy carbide layers has a shorter creep rupture life than that with zig-zag grain boundaries with precipitation of coarse carbides. ${ }^{6}$ ) However, the mechanism for different morphology is not clear. Since the heat treatment was performed in an identical conditions, it must be due to a procedure before it, i.e., to the HIP or to the forging. If the difference is due to the HIP, the lower HIP temperature must be the reason for the simple boundary structure of Specimen C because it was $100 \mathrm{~K}$ lower for Specimen C. In our view, however, it is more likely due to the forging. A grain boundary structure similar to the simple one had been confirmed in the Specimens D and E after heat treatment. These specimens were forged in the same condition as Specimen $\mathrm{C}$ while they were HIP-treated at a temperature $180 \mathrm{~K}$ higher than it.
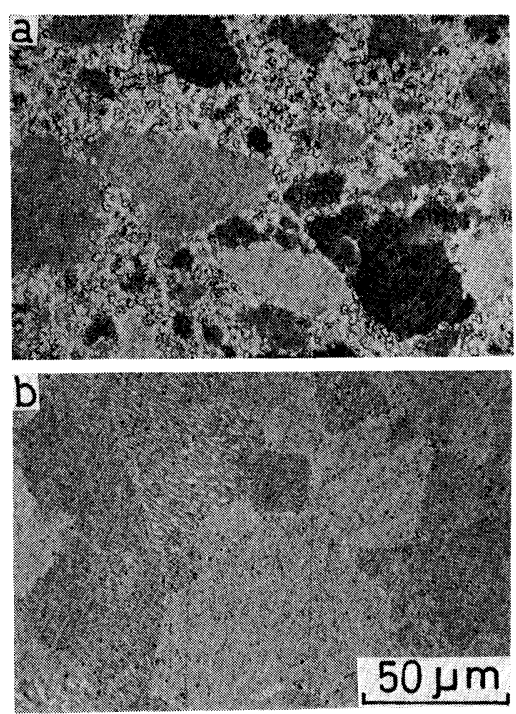

(a) Before heat treatment

(b) After heat treatment

Fig. 4. Microstructures for Specimen C.

\section{Effect of Attritor Treatment}

Because powder from LHC process contained (and still contain in a commercially available conditions) a substantial amount of coarse particles, it was necessary to discard a considerable part of the obtained powder before HIP or to perform superplastic forging at a slow rate if a satisfactory forging is to be achieved with the powder of this origin. As a manoeuvre to eliminate this burden, an attempt was made to give stress to powder grains prior to HIP by an Attritor. Specimens D and E in Table 2 were prepared from the powders treated in this way.

This attempt was very successful as for the intended purpose, namely to perform the superplastic forging with coarse powder. Nevertheless, it was not so as for a final end, i.e., to obtain components with an excellent performance. Although the maximum pressure required for their superplastic forgings decreased drastically as compared to the case for Specimen C, mechanical performance deteriorated as drastically. The deterioration was more evident for the specimen after the longer treatment or after heat treatment.

The poor performance of the heat treated specimens is attributed to the voids in them. In the case of the heat treated specimens, this is easily proved by a close check of the optical micrographs. They are well illustrated in the micrographs for the heat treated Specimens D and E shown in from Figs. 5(e) through $5(\mathrm{~h})$. In these microstructure many voids are evident in the longitudinal planes (the planes along the forging direction), while they are not so in the transverse ones. The pancakes from Attritor treated powder contain a number of voids compressed into flat-ellipsoids with their main axis aligned in the directions normal to that of the forging. The role of the voids are well demonstrated by the micrographs in Fig. 6 in which a fracture surface from the specimen with the smallest elongation (Specimen E) is compared to the specimen with the largest elongation 

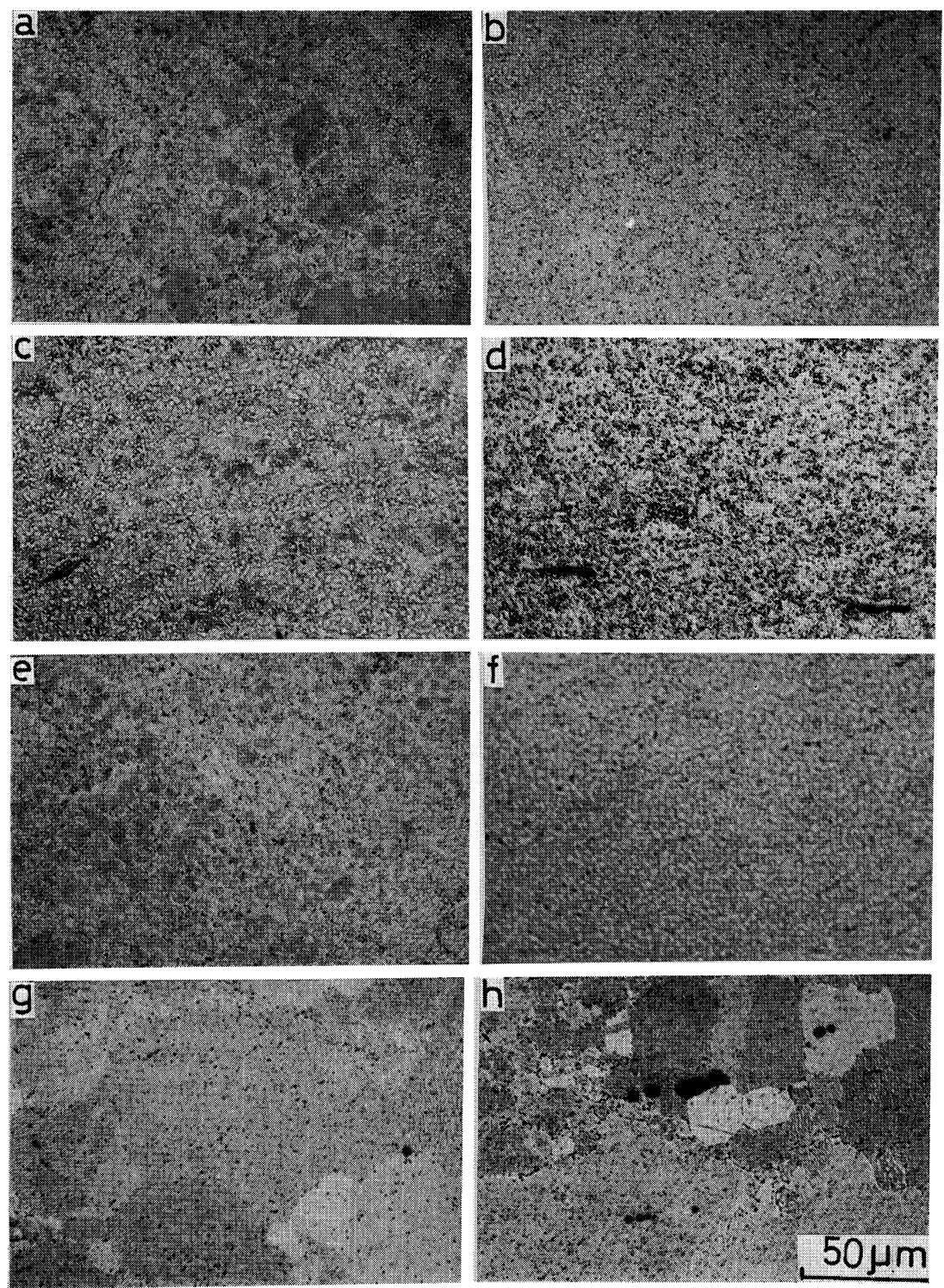

(a) Across pressing direction, before heat treatment, for Specimen D

(b) Across pressing direction, before heat treatment, for Specimen $\mathrm{E}$

(c) Along pressing direction, before heat treatment, for Specimen D

(d) Along pressing direction, before heat treatment, for Specimen $\mathrm{E}$

(e) Across pressing direction, after heat treatment, for Specimen D

(f) Across pressing direction, after heat treatment, for Specimen $\mathrm{E}$

(g) Along pressing direction, after heat treatment, for Specimen D

(h) Along pressing direction, after heat treatment, for Specimen $\mathrm{E}$

Fig. 5.

Microstructures for Specimens D and E.
(Specimen G). A number of voids are seen on the fracture surface of the brittle Specimen E.

The fall of the performance of the as-forged pancakes may be caused by slightly different reasons as well. As is seen in the pictures from Fig. 5(a) through $5(b)$, their structures were so specific that they significantly differed from those of any other specimens including the specimens after heat treatment of the same origin. Their first structural feature was a layer structure running across the forging direction seen in the longitudinal cross sections. Along these layered structures many structural flaws, oblong along the layers, are seen as if they were cracks or crevices. Their second is the very isotropic and homogeneous structure seen in the transverse cross sections. Although this cross section is still patchy after $1 \mathrm{~h}$ of attrition, it was almost thoroughly homogeneous after $7 \mathrm{~h}$ (Figs. 5(a) and 5(b)). Whereas the voids were not obvious in this cross section as far as observed with an optical microscope, they were found here and there by a scanning electron microscope. Figure 7 is an example of them, where chains of voids appear rather like cracks. The pancakes from Attritor treated

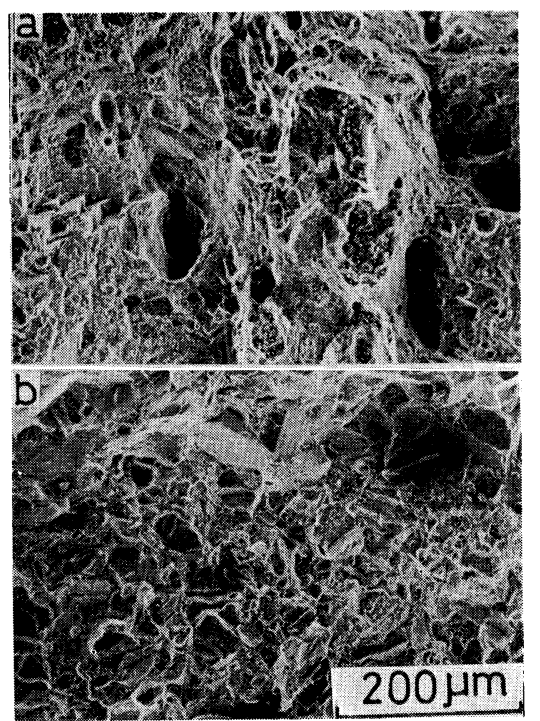
(a) Specimen E
(b) Specimen $\mathrm{C}$

Fig. 6. Fractured surfaces of heat treated Specimens $\mathrm{C}$ and E. 


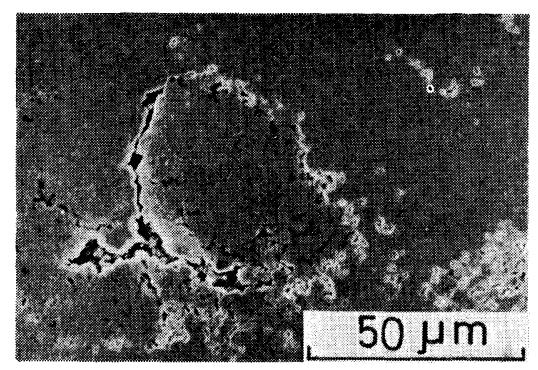

Fig. 7. Array of voids seen in the Specimen $\mathrm{E}$ before heat treatment.

powder immediately after the forging contained not only genuine voids but also the cracks arising from poor cohesion or retention of the Attritor treated powder particles. This means that the poor mechanical performance of these specimens are caused not only by the voids but also by lower strengths of matrix due to poor cohesion and to retention of the powder.

\section{Conclusions}

An investigation was carried out about effects of processing factors on mechanical properties of the " pancakes" (thick circular discs) prepared by superplastic forging of a HIP-consolidated nickel-base alloy powder. Main points of the obtained information were as follows.

(1) Superplastic forging of a HIP-consolidated material from under-60-mesh powder could be satisfactorily performed only at as half a rate as that of under-150-mesh powder at $1373 \mathrm{~K}$. Mechanical performance of the pancakes was, however, a little better for the pancakes from the coarse powder.

(2) Comparison of a pancake forged at a high temperature and low speed with that at a low tem- perature and high speed showed, after a heat treatment, a softer behaviour, i.e., a larger elongation by tensile testing and a shorter life by creep rupture testing, respectively, at $1033 \mathrm{~K}$.

(3) When alloy powder was stressed before HIPconsolidation, superplastic forging could be performed by far smaller pressure, while mechanical performance of the obtained pancakes was deteriorated as much.

\section{Acknowledgements}

Authors acknowledge valuable contributions of Daido Steel Co., Ltd., Kobe Steel, Ltd. and Sumitomo Electric Industries, Ltd. This work was performed as a part of the $\mathrm{R} \& \mathrm{D}$ Project of Basic Technology for Future Industries sponsored by Agency of Industrial Science and Technology, Ministry of International Trade and Industry.

\section{REFERENCES}

1) V. A. Tracey and C. P. Cuttler: Powder Met., 24 (1981), 32.

2) H. Harada and M. Yamazaki: Tetsu-to-Hagané, 65 (1979), 1059.

K. Kusunoki and M. Yamazaki: Tetsu-to-Hagané, 70 (1984), 719.

3) T. Kato, K. Kusaka, T. Horata and J. Ichikawa: Tetsuto-Hagané, 71 (1985), 719.

4) H. Takigawa: Preprint of "Dai-3-kai Jisedai Sangyokiban Gijutsu Shinpoziumu-Kinzoku.Fukugozairyo Gijutsu-, Paper No. M-3-2, Jisedai Kinzoku•Fukugozairyo Kenkyu Kaihatsu Kyokai, Tokyo, (1985), 199.

5) J. F. Barker and E. H. van der Molen: Superalloys-Proc. 2nd Intern. Conf., Metals and Ceramics Inform. Cent., U.S.A., (1972), AAl.

6) C. H. White: The Nimonic Alloys, ed. by W. Betteridges and J. Heslop, Edward Arnold, London, (1974), 83. 